\title{
Erratum to: Development of a combined SEM and ICP-MS approach for the qualitative and quantitative analyses of metal microparticles and sub-microparticles in food products
}

\author{
D. Beltrami • D. Calestani • M. Maffini • M. Suman • \\ B. Melegari • A. Zappettini $\cdot$ L. Zanotti $\cdot$ U. Casellato •
}

M. Careri • A. Mangia

Published online: 15 July 2011

(C) Springer-Verlag 2011

Erratum to: Anal Bioanal Chem

DOI 10.1007/s00216-011-5149-2

The publisher

The publisher regrets that a mistake in the title of this contribution was made in the final proof of this contribution. The title should be:

Development of a combined SEM and ICP-MS approach for the qualitative and quantitative analyses of metal nanoand microparticles in food products

Our sincere apologies to the authors.

The online version of the original article can be found at http://dx.doi. org/10.1007/s00216-011-5149-2.

D. Beltrami $\cdot$ M. Maffini $\cdot$ M. Careri $(\bowtie) \cdot$ A. Mangia

Dipartimento di Chimica Generale ed Inorganica,

Chimica Analitica, Chimica Fisica,

Università degli Studi di Parma,

Parco Area delle Scienze 17/A,

43124 Parma, Italy

e-mail: careri@unipr.it

D. Calestani $\cdot$ A. Zappettini $\cdot$ L. Zanotti

IMEM-CNR,

Parco Area delle Scienze 37/A,

43124 Parma, Italy

M. Suman · B. Melegari

Barilla Food Research Labs,

via Mantova 166 ,

43100 Parma, Italy

U. Casellato

ICIS-CNR,

Area della Ricerca, C.so Stati Uniti 4,

35127 Padova, Italy 